\title{
Airport Merchandising Using Micro Services Architecture
}

\author{
Hari Bhaskar Sankaranarayanan \\ Amadeus Labs, Bangalore, 560087, India \\ E-mail: hari.sankaranarayanan@amadeus.com \\ Viral Rathod \\ Amadeus Labs, Bangalore, 560087, India \\ E-mail: viral.rathod@amadeus.com
}

\begin{abstract}
Airport offers an ecosystem where passengers, airlines, airport, and merchants meet under one roof during travel. During the journey, there is a good amount of time spent by passengers on waiting or transit before boarding the flight. Passengers look for spending that time by shopping, dining, and entertainment. Airport merchants and airlines look for merchandising opportunities to acquire new customers, up-sell, and cross-sell their products and services. Highly personalized merchandising offers can be generated on the fly by combining contextual information from passenger profile, likes and interests, merchant offers, and location specific events, seasons, and festivals. To achieve this, a strong airport merchandising platform is needed. The goal of the airport merchandising platform is to exchange information in a seamless manner across travel systems. The platform is designed on microservices design principles that use information from airlines, airport, social media, and merchant systems. Microservices can promote quick development, deployment, and realization of services. Microservices also improve the time to market capabilities. Mobile and desktop applications consume them to offer a personalized shopping experience to the passengers.
\end{abstract}

Index Terms-Microservices, airports, merchandising, personalization, architecture, airlines, social.

\section{INTRODUCTION}

During the air travel journey, wait time at airports is dependent upon travel location like international or domestic, nature of airport passenger traffic like a congested city airport, time of the day, security check, immigration queue and seasons like holidays, festivals, and events. Modern airports across the world offer a variety of options to utilize this wait time in the form of duty-free shopping, dining, airline lounges, transit hotels, sleeping areas, spas, transit tours, events and entertainment. Merchandising is gaining popularity among airlines, and airport merchants as it opens up avenues for new collaborative business models. It is also a key growth driver for airlines, airport merchants to sell products and services by utilizing the quality interaction time with passengers. Market research mentions that there is a great revenue opportunity for duty-free shopping [1] and merchants can acquire customers by creative methods like personalization, discounts, and mobile shopping experience that can offer competitive advantage [2]. Personalization is about knowing the passenger needs and offering the right products and services at the right time at the right location by analyzing the past history like shopping preferences, likes, demographics, culture and other specific individual attitudes. Social media profile and activity of the passenger can help to capture some of those individual attributes. On the flip side, there is a challenge to achieve such personalized travel experience since the underlying travel information systems operate in their own silos or sandboxes [3] that don't promote the exchange of data in a seamless way. It limits the potential of targeted merchandising opportunities for airport merchants since it is hard to get passenger information and at times it is restricted only to few players in the ecosystem like airlines.

In air travel industry the systems are built for a specific goal or a function, Ex: Airline departure control system is built for flight management and on boarding passengers within stipulated time. Passenger Name Record (PNR) is restricted to Airlines, Global Distribution Systems (GDS) and airports during the trip. It is not easily available for merchants to collect information about passengers. Also, airline travel systems are heterogeneous in nature [4] and makes it complex to integrate with retail systems. International Air Transport Association (IATA) made rapid strides in the past to promote seamless integration capabilities amongst airlines to promote merchandising, airline retailing through New Distribution Capability (NDC) standards [5]. While the realization of such efforts made good progress in past years [6], the paper supports such industry standards and also proposes a novel method of using Microservices Architecture (MSA) to build a merchandising platform for solving merchandising at airports. The platform promotes sharing of information through a common set of micro services that can be developed and deployed quickly for use in passenger facing mobile and desktop applications.

The paper is organized into following sections. Section 
2 discusses the motivation and current challenges, section 3 highlights the related work in literature and industry, section 4 introduces the merchandising platform based on MSA, section 5 discusses the results of prototype scenarios, section 6 highlights directions for future work and section 7 concludes the paper.

\section{Motivation AND CURRENT CHALLENGES}

Travel shopping experience is very subjective to the attitude, preferences of a passenger and poses a challenging landscape of integrating multiple data points from the underlying travel systems to know more about the passenger. The problem to assimilate, and infer information from various distributed travel systems to build a relevant and personalized recommendation is nontrivial. This is due to the variety and veracity of data sources [7]. The functional and technical concerns of developing such an integrated platform are discussed in the following sections:

\section{A. Passenger profile}

Passenger profile means know-how of passenger personal information including demographics, likes, dislikes, preferences, and attitudes. While social media are available to gauge the tastes of the passenger, the availability, and access to such information is complex. Privacy issues and concerns at times outweigh the benefits, hence, it is important to understand the passenger to a reasonable extent, especially the past purchase history, type of passenger like young, adult, senior citizens etc. This is a key component of knowing about the passenger more which is difficult to obtain in a straight forward manner. This requires user consent on social media data and, or sharing PNR details.

Airlines systems do capture some personal attributes through loyalty systems, and customer relationship management tools, especially for frequent flyers, however it is not easy to leverage the information across travel service providers if the passenger chooses different airlines like code share, or fly on Low-Cost Carriers (LCC) where such loyalty programs don't have much significance as they are already assimilated as no-frills, ancillary based business models [8].

\section{B. Information sharing}

Travel systems operate in silos based on the stages of passenger journey. Travel booking systems like online portals are managed through Online Travel Agents (OTA) systems which interact with GDS for the booking process. Airline systems are built for specific goals like departure control, inventory management, revenue management and loyalty management. The connecting link between such systems is the travel record shared among them in the PNR form.

Similarly for airports, there is a central repository like Airport Operations Database (AODB), which exchanges information between airlines, airport operations and airport service providers. The merchant shopping systems including catalog, billing, and payment systems are typically built outside the scope of airlines, airports, and GDS systems. Also, airlines prefer the mode of in-flight shopping services and offer a strong competition to onpremise airport merchandising models. The competition also restricts information sharing by the virtue of having different business goals. Social networks like Facebook and Twitter doesn't directly connect to underlying travel systems. They are typically used for sharing and providing a word of mouth reviews to their friends circle. Thus, passenger preferences and profile is stored and managed in different ways across various systems making it harder for sharing. There is no one source of truth about the passenger personal preferences that exists among all the players.

\section{Technology evolution}

Core constituents of travel systems especially GDS are built on legacy systems like Transaction Processing Facility (TPF) [9] based on mainframes. The legacy standards like EDI [10] is extensively in use. It is a challenge to prevent technical diversity since the systems were developed during different horizons by forming airline alliances, acquisitions and mergers [11]. The airline and GDS applications traditionally are businessto-business (b2b) oriented providing services for airline websites, airline customer service, and travel agents across the globe to make travel bookings. This is in sharp contrast with modern OTA and Low-Cost Carrier (LCC) airlines which operate on direct distribution channel based business-to-consumer (b2c) applications where technology disruptions are quite common. Modern travel technology stack built for b2c applications provide access to Application Programming Interfaces (API) to ease interactions and adopt protocols like Webservices and Representational State Transfer (REST) [12]. Thus, the vast spectrum of technology landscape makes it harder to converge on common paradigms and standards.

\section{Offer relevance}

In the current setup, airport deals and promotions from merchants are not targeted. As per market research reports, passengers are willing to share personal preferences for getting personalized shopping recommendations [13]. Poor relevance can make it harder to build the expected reach that can generate good leads and increase footfall. The lead conversion metric will be impacted if it is not relevant. For example, a senior citizen passenger may need travel pillows for neck rest, family or group travel may look for popular souvenirs, teens may look for something trendy. The list may go on based on the passenger type under consideration. As highlighted earlier, it becomes harder for merchants predict the offers that resonate with the passenger needs. More importantly wrongly targeted deals might lead to dissatisfaction and reduce shopping interests.

\section{E. Time to market needs}

Developing an airport merchandising system that offers personalization by integrating multiple travel systems involves time and effort. As highlighted in 
previous sections, the information exchange and underlying system complexities prevent the ability to access passenger information. Also, the merchants may not have significant investments to build a platform that would serve them the purpose and maintain them on a continuous basis. With the advent of mobile devices and diverse passenger needs the platform must be nimble enough for adapting to the changes. The main limitation of monolithic architectures, developed on conventional systems like Service Oriented Architecture (SOA) is that it takes more time to build changes and test them. Also, the need is to leverage the existing systems opportunistically without making too many changes in the underlying layers.

\section{F. Motivation}

The objective is to build a platform without substantial investment, leveraging existing travel information assets and sharing them for a specific goal of merchandising.

MSA is quite popular in recent times with organizations like Amazon, Google, Netflix, Soundcloud, and Microsoft Azure. The online platforms are built on MSA principles that provide specific services called smart end points that are quick to develop, deploy on lightweight containers which are isolated, highly available and scalable [14] [15] [16]. Travel systems form an interesting case of applying MSA since it provides an opportunity to develop smart end points from existing systems without much effort by serving JSON messages through REST endpoints. MSA uses principles like single responsibility which enables the underlying system to provide a specific service without making many changes to the complete stack. MSA is agnostic of the underlying complexity of the technology stack, protocols and development processes etc. It opens an avenue of the community collaboration model, to build a new set of applications for passenger needs. In the next section of related work, there are some examples from literature and industry where attempts to realize such systems are made.

\section{RELATED WORK}

IATA defines several standards and frameworks for information exchange across travel systems. The standards include Passengers and Airport Data Interchange Standards (PADIS), NDC and Common Industry Data Model [17]. They have working groups for such topics and provide implementation guidelines for the airport, and airline systems. IATA extensively promotes sharing contents for airline merchandising. IATA proposes XML as a format for information exchange especially to address NDC.

Airport systems use Common Use Terminal Equipment (CUTE) standards. There is a debate on moving towards a common standard for interaction like Common Use Passenger Processing Systems (CUPPS) proposed by IATA [18].

Helsinki airport, Finland has REST services published for airports, airlines to help developers in building apps for airport services [19]. Helsinki airport conducted a hackathon event inviting developer community to build apps based on the service catalog [20]. This is a thought provoking move that opens up community contribution towards building air travel applications. It provides a strong motivation to envision architectures to enable such initiatives. It provides openness towards data access and can support building multiple airport apps.

MSA has become prominent since 2011 and architecture experts like Martin Fowler has written blogs about the same [21]. The relevance and need of MSA over SOA is also discussed. MSA is proposed as a viable architecture during early studies for building smart city technology infrastructure using Internet of Things (IoT) [22]. It also provides us an inspiration to evaluate a similar approach for a domain like travel where distributed architectures are quite common with various actors and systems in play.

User profile based personalized research paper recommendation system explains an approach of mining research papers based on inference from user interests [23]. The user profile is classified hierarchically in this approach with the domain, topic, and keywords based on past data. In our paper, there is no direct hierarchy involved in building the user profile, but the classification of attributes is done on the basis of passenger social data and trip context.

\section{ARCHITECTURE OF AIRPORT MERCHANDISING PLATFORM}

The goal of merchandising platform architecture is to develop microservices from existing systems through abstraction principles without much of the development efforts. The services should be self-contained, and simple to consume for meeting specific needs of merchandising and personalization. The building blocks of this architecture are:

1. The underlying information systems run the business logic (Airlines, Airport, Social media, Payments)

2. Microservices layer exposed in form of REST APIs

3. The passenger facing applications like mobile, and desktop provide a front end to the passengers.

Fig.1 represents the architecture of the airport merchandising platform.

The following section highlights the list of nonexhaustive microservices that can be developed from the underlying components/systems:

\section{Airline Systems:}

PNR fields display like the class of travel, meal preferences, and loyalty information like past travel history.

\section{Airport Systems:}

Location navigation, tax refund claims and shop details. 


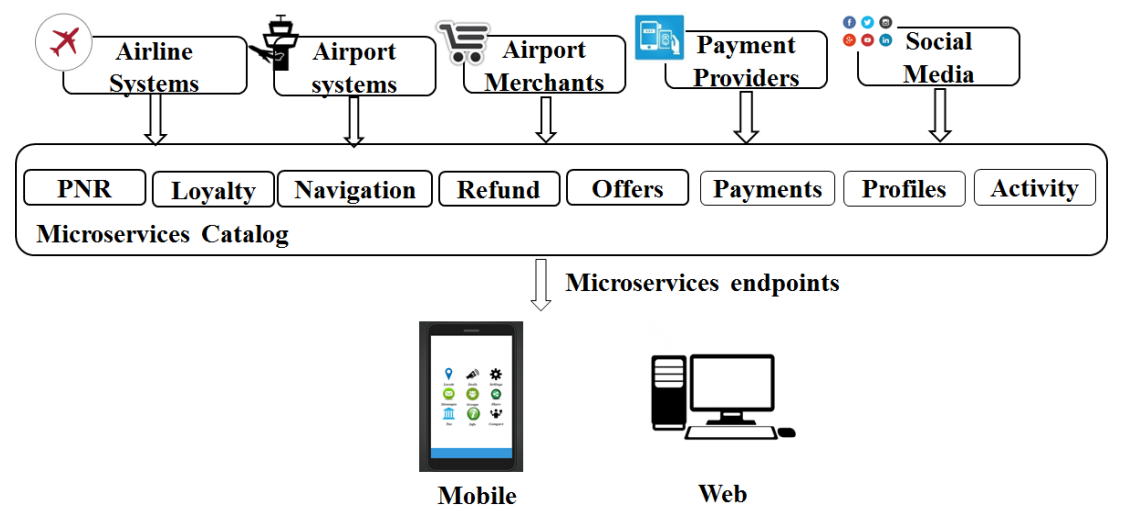

Fig.1. Microservices architecture for Airport Merchandising

\section{Merchant Systems:}

Offers, and tax refund calculator.

\section{Payment Providers:}

Payments using various modes of payment like cash, card, and mobile wallets.

\section{Social Media:}

Public profile and activity feed.

Offers can be uploaded by merchants using simple excel spreadsheet formats on a periodic basis on the Airport merchant system upload interface. Offer micro service will list the offers and make it available to other apps.

Microservice catalog is the lightweight registry lookup mechanism to register, identify and use the microservices which require authentication, authorization from the service provider and consumers for establishing some form of governance. The governance is minimal compared to traditional SOA since microservices platform provides granular services that can be replaced, retired and enhanced to offer new services. The client applications need to consume the changes to get the benefits of new version upgrades.

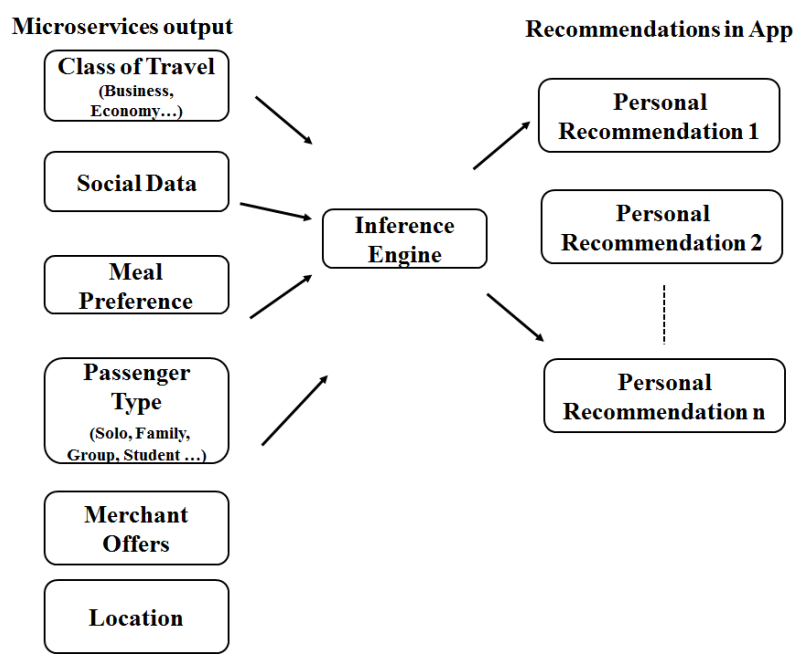

Fig.2. Microservices output for personalized recommendations
Airport mobile applications, desktop applications at airports can consume the above services to develop recommendations for the passenger. Fig 2 represents a recommendation system that runs on a mobile app which consists of an inference engine that consumes the output of microservices. The inference engine is built on a simple rule-based approach using Javascript with lookup $\&$ match logic based on selected attributes.

A prototype is built using the merchandising platform. In the next section, it is discussed in detail by elaborating the functional use cases, technical details of the platform and working of the inference engine that generates bestpersonalized recommendations.

\section{RESULTS AND DISCUSSIONS}

The merchandising platform is tested with specific use cases that consists of a combination of functions that involve microservices of airport, merchants, airlines, payment, and social media systems. The scenarios for the prototype are:

1. Personalized offers on the mobile based on passenger type

2. Tax refund calculation for the specific airport

3. Navigation to a specific location in the airport

The prototype is built on mobile using responsive user interface based on HTML5, and Javascript. The development is done through Appery.io a cloud-based enterprise mobile app builder [23]. Passengers register in the app using social media accounts like Facebook or Google. They agree to share profile information during the sign-up phase of the process for receiving personalized recommendations. They can enter PNR information under trip details in the settings page. Fig 3 demonstrates a use case where the passenger is offered a personalized deal. The deal about a high tech speaker of a well-known brand is presented based on the passenger preference on gadgets and music.

The inference is derived by understanding the social profile of the user based on interest pages, class of air travel and matching with the list of offers from the 
merchant. In this specific scenario, the inference engine uses "PNR" microservice to get the class of travel, passenger type, "Social" microservice to parse the age, and interest attributes. Once the attributes are selected, it is matched with the "Offer" microservice output to make the right set of offers. Passenger type is a key attribute that inference engine looks at to choose the right set of offers to be recommended first.

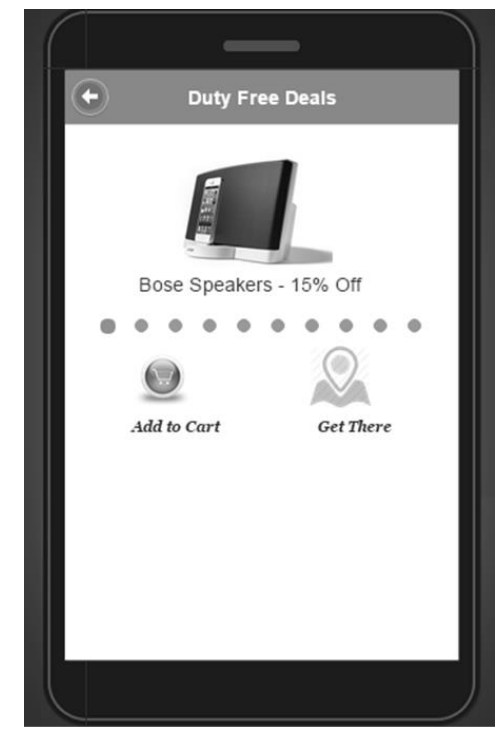

Fig.3. User Interface - Personalized Offers

In another scenario depicted in Figure 4, the passenger is identified as a senior citizen type from the PNR microservice and the offer matching with a travel kit is recommended first. The social profile information is not chosen in this case since the inference engine applies precedence for passenger profile over social data.

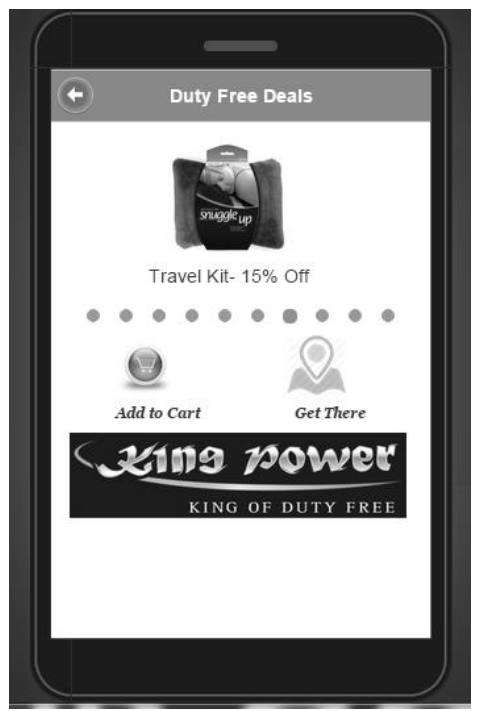

Fig.4. User Interface - Personalized Offer for Senior Citizens

Fig 5 depicts a personalized offer matched based on passenger gender which is inferred as female and the interest from Facebook profile towards designer pages.

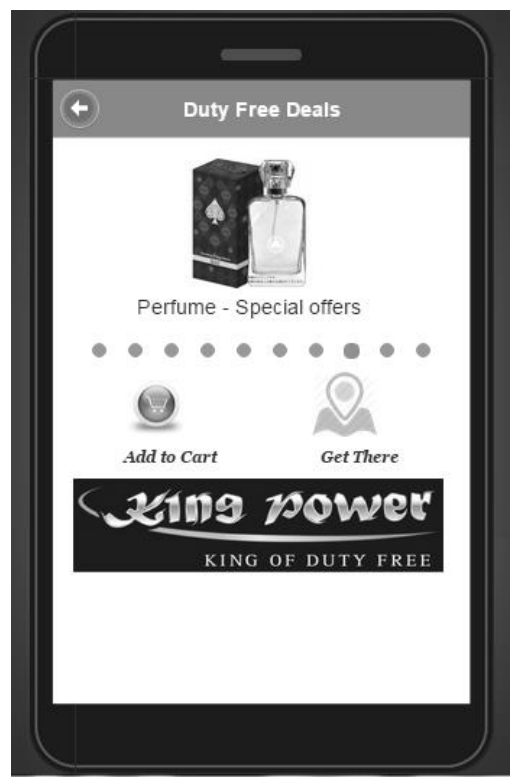

Fig.5. User Interface - Personalized Offer on Perfumes

Fig 6 depicts the "Tax refund calculation" microservice where the passenger can calculate the refund value based at the airport country location. The applicable tax rate is returned based on current location details. Furthermore, the passenger can locate the refund counter and file a claim through a "Tax Refund Claim" microservice. The microservice will consume location details as an input and return the applicable tax details.

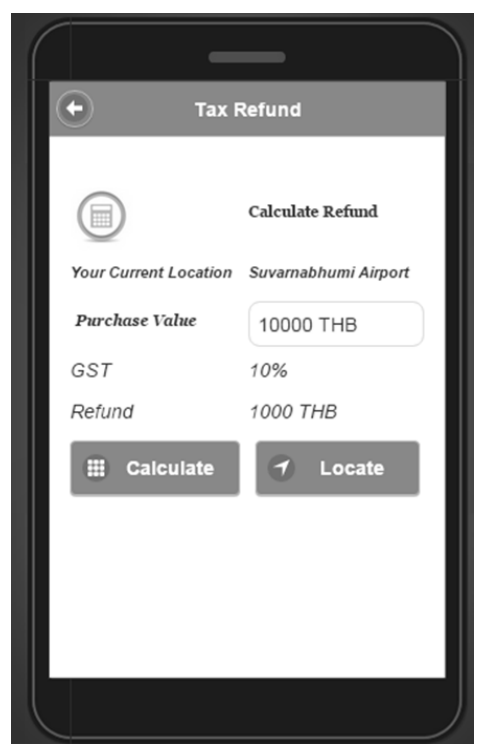

Fig.6. User Interface - Tax Refund

Fig 7 depicts "Navigation" microservice that provides shop location on airport navigation map. The navigation details are returned from the airport floor layout plan. This will be a valuable microservice to trace the exact shop that are pushing the offers. 


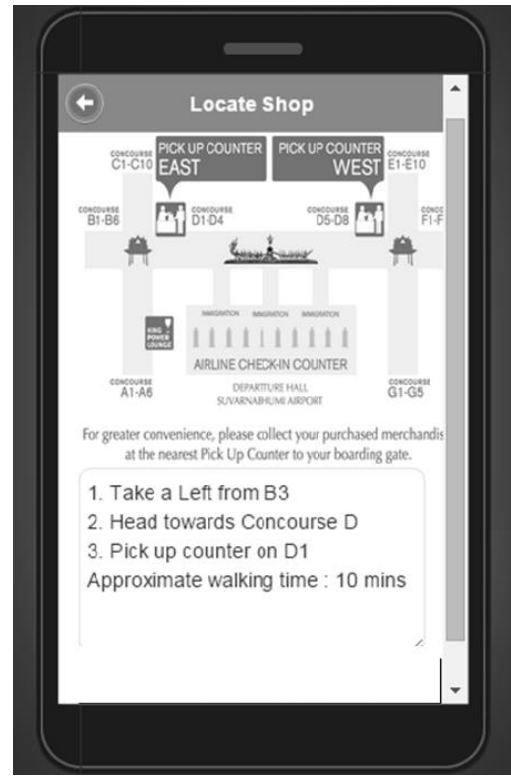

Fig.7. User Interface - Shop Navigation

The server side programming is done using Java platform for this prototype. JSON wrappers are created from the output of Airline, Airport systems on the specified functions. The following section highlights JSON response output returned for the Offers, Social profile, and PNR microservices.

Fig 8 represents the JSON output of offers with merchant information, product description, type, and discount details.

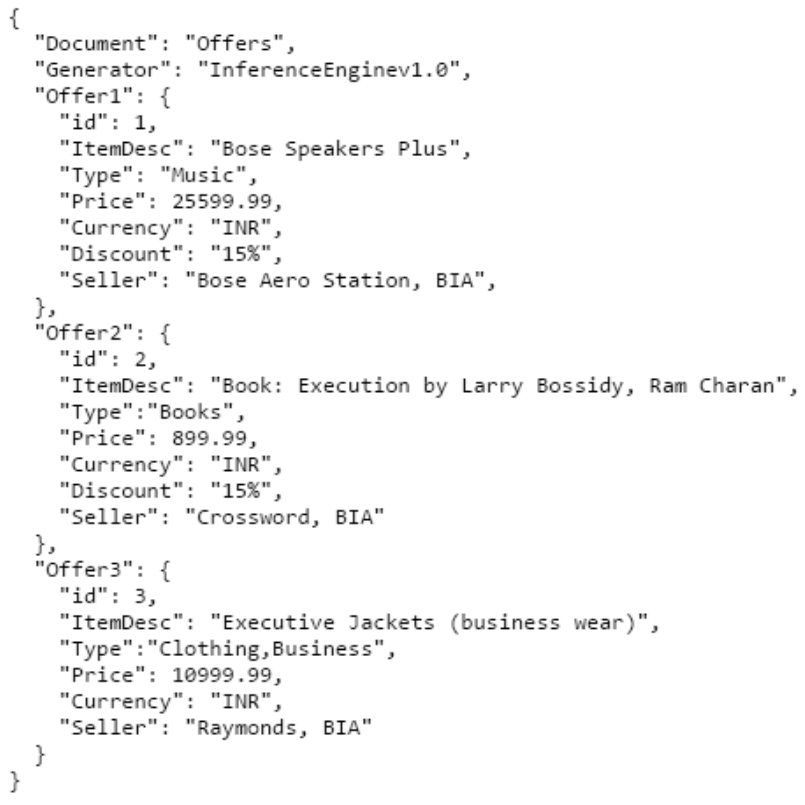

Fig.8. Offer response JSON

Fig 9 represents the JSON output from a Facebook public profile with specifics on interests, personal information like date of birth.

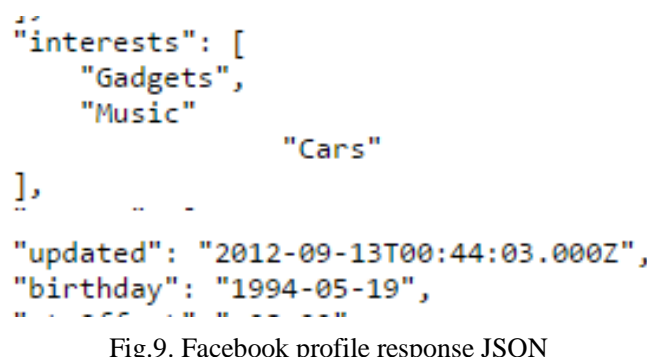

Fig 10 represents PNR JSON output providing information on the class of travel, passenger type, and meal preference. The input to the microservice is the PNR number. The underlying airline or GDS systems may go through migration or upgrades, PNR details can come from different providers like full-service carriers (FSC) or LCC. The smart end point of MSA ensures that it is decoupled from such changes. As long as the end point is honoring the REST contract, the client applications don't require any change.

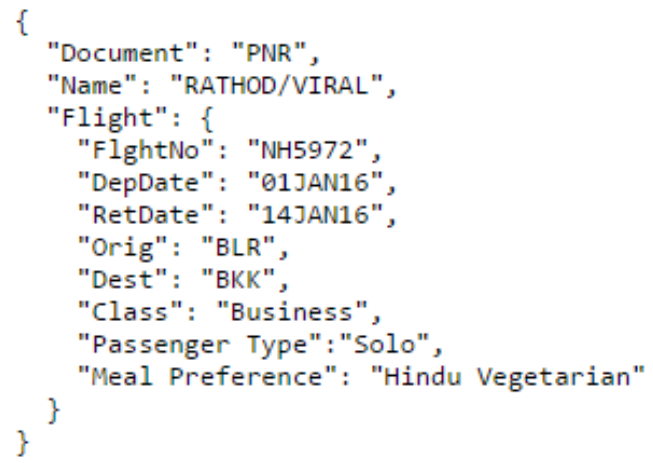

Fig.10. PNR response JSON

Also, further use cases include an airport restaurant application can consume "PNR" microservice to get passenger meal preferences and push offers based on meal choices. The ecosystems of airport applications will use the same microservices infrastructures to look up and consume the services to solve the specific need of passengers.

The scenario testing demonstrates that merchandising platform can generate personalized recommendations and display on a mobile device based on the inputs received from various systems using microservices.

\section{FUTURE WORK}

MSA is a cutting-edge area where new business models can evolve on the underlying business systems. The existing airline, airport applications can be comprehensively assessed for evolving the set of target architectures based MSA principles. The inference engine for developing personalized recommendations can be developed as a new microservice for the rest of the travel applications to consume. It can be made more 
sophisticated with browsing history, and past purchase records thus improving relevance and quality of recommendations. More advanced algorithms and machine learnings techniques can be applied for generating a personalized recommendation based on the attributes under consideration. Also, this prototype can be further tested using cloud providers like Amazon, Google cloud for scaling and reliability. A detailed performance study with metrics can be conducted on the live application by changing requirements, scalability needs to assess costs in terms of maintenance, deployment, and time to market. The prototype can be converted into a full-fledged mobile application, which can be deployed as a pilot in airports.

From the industry standards development point of view, a collaboration study can be initiated with IATA working groups on NDC, PADIS and Industry data models to identify opportunities for MSA and propose reference architecture recommendations for airlines and airports. MSA can be recommended as an evaluation choice for NDC for airlines and extend it as a reference architecture for merchandising scenarios.

\section{CONCLUSION}

MSA viability is proven with leading industry players adopting it completely as a part of building distributed architecture capabilities. Merchandising platform with personalization is a great tool that enables passengers to shop right and increases airlines, merchant revenue opportunities. Airlines are evolving new business models by selling ancillaries, and collaborating with partners like airports, merchants to push sales during the trip. Lowcost carriers are a great example for pioneering the merchandising products at the time of booking and post booking. Airlines are following similar route towards selling ancillaries and tap the merchandising opportunities. Passengers, the center of travel ecosystem are getting prominence since knowing more about them and offering the best-in-class travel experience is imperative for building loyalty. This opens up new avenues of collaboration and establishes a strong case for the common data model, design, and architecture. Airport merchandising platform, built using MSA is easy to develop and deploy within a shorter time frame. MSA tackles the heart of the travel system's heterogeneity by abstracting the complexity, providing specific business function and promoting content sharing across travel service providers. MSA also aligns with the approach of defining industry standards on the data model, content interchange, and passenger-centric services.

\section{REFERENCES}

[1] PRNewswire. Duty-Free Retailing Market Sales worth $\$ 73.6$ Billion by 2019. http://www.prnewswire.com/newsreleases/duty-free-retailing-market-sales-worth-736billion-by-2019-500938661.html (last accessed Dec 2015).

[2] Luxury Daily. Location-tailored boutiques provide personalized shopping experiences. http://www.luxurydaily.com/location-tailored-boutiques- provide-personalized-shopping-experiences/

(last accessed Dec 2015).

[3] Data Informed. Why the Travel Industry, Long DataDriven, Needs to Step Up Its Game.http://datainformed.com/travel-industry-long-data-driven-needsstep-game (last accessed Dec 2015).

[4] NIIT. Airline-Traveler Relationship: Changing Paradigms with NDC. http://www.niittech.com/sites/default/files/Airline\%20Traveler\%20relatio nship\%20-

$\% 20$ Changing\%20Paradigms\%20with\%20NDC.pdf (last accessed Dec 2015).

[5] IATA, IATA New Distribution Capability Standards: Implementation Guide 2.0. https://www.iata.org/whatwedo/airlinedistribution/ndc/Documents/ndc-implementation-guidev2.pdf (last accessed Dec 2015).

[6] Tnooz. IATA claims solid progress with its New Distribution Capability.http://www.tnooz.com/article/iataclaims-solid-progress-with-ndc-for-airline-distribution/ (last accessed Dec 2015).

[7] Sabre. Whitepaper on the Evolution of Customer Data, Sabre Airline Solutions. http://www.sabre.com/insights/airline-customer-datachallenges-and-complexities/ (last accessed Dec 2015).

[8] Tomová, Anna, and Lucia Ramajová. Frequent Flyer Programs and Low-cost Airlines: Ongoing Hybridization?. Procedia-Social and Behavioral Sciences 110, 2014.p 787-795.

[9] Wikipedia. Transactional Processing Facility. https://en.wikipedia.org/wiki/Transaction_Processing_Fac ility (last accessed Dec 2015).

[10] Cerasis. Electronic Data Interchange or EDI in Transportation: Breaking Down What it is and How It Works. http://cerasis.com/2014/12/11/edi-intransportation/ (last accessed Dec 2015).

[11] Hospitalitynet, Global Distribution Systems in Present Times. http://www.hospitalitynet.org/news/4013406.html (last accessed Dec 2015).

[12] Programmableweb. 134 Travel APIs: Kayak, Yahoo Travel, and HotelsCombined. http://www.programmableweb.com/news/134-travel-apiskayak-yahoo-travel-and-hotelscombined/2012/02/28 (last accessed Dec 2015).

[13] NCR, A Retail Evolution in Travel. http://www.ncr.com/wp-content/uploads/retail-revolutiontravel-wp.pdf (last accessed Dec 2015).

[14] PWC, Agile coding in enterprise IT: Code small and local. http://www.pwc.com/us/en/technology-

forecast $/ 2014 /$ cloud-

computing/features/microservices.html (last accessed Dec 2015).

[15] Business Insider. Big companies and startups alike are jumping all over a trendy new tech called 'microservices' here's why. Business Insider website. http://www.businessinsider.in/Big-companies-andstartups-alike-are-jumping-all-over-a-trendy-new-techcalled-microservices-hereswhy/articleshow/47904028.cms (last accessed Dec 2015).

[16] IEEE Software Engineering. Microservices.http://ieeexplore.iee.org/stamp/stamp.jsp? arnumber=7030212 (last accessed Dec 2015).

[17] IATA. IATA Airline Industry Data Model, http://www.iata.org/whatwedo/passenger/Documents/Airli ne-Industry-Data-Model-PPT.pdf (last accessed Dec 2015).

[18] Futuretravelexperince. The future of airport common use 
- will a one-size-fits-all solution ever be feasible?. http://www.futuretravelexperience.com/2014/07/futureairport-common-use-will-one-size-fits-solution-everfeasible/ (last accessed Dec 2015)

[19] Finnair. Slush API. https://slush.ecom.finnair.com/docs/\#1 (last accessed Dec 2015).

[20] Finnair. Finnair, Helsinki Airport and Reaktor challenge developers to create new services to air travelers.http://www.finnairgroup.com/mediaen/mediaen 7.html?Id=xml_2026732.html (last accessed Dec 2015).

[21] Martin Fowler. Microservices. http://martinfowler.com/articles/microservices.html (last accessed Dec 2015).

[22] Krylovskiy, Alexandr, Marco Jahn, and Edoardo Patti. "Designing a Smart City Internet of Things Platform with Microservice Architecture." Future Internet of Things and Cloud (FiCloud), 2015 3rd International Conference on. IEEE, 2015.

[23] Hong, Kwanghee, Hocheol Jeon, and Changho Jeon. "UserProfile-based personalized research paper recommendation system." Computing and Networking Technology (ICCNT), 2012 8th International Conference on. IEEE, 2012.

[24] Appery.io. Available: https://appery.io/ (last accessed Dec 2015)

\section{Authors' Profiles}

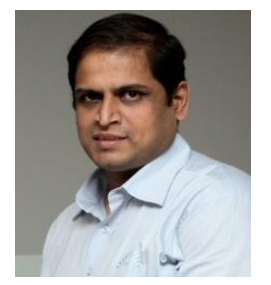

Hari Bhaskar Sankaranarayanan is working in the area of travel research, product development, and engineering. His interests include enterprise architecture, the design of distributed systems, software quality and programming languages.

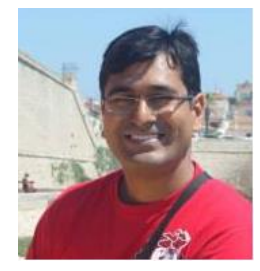

Viral Rathod is working in the area of travel research, search quality monitoring product development. His interests include machine learning, information retrieval and software architecture.

How to cite this paper: Hari Bhaskar Sankaranarayanan, Viral Rathod,"Airport Merchandising Using Micro Services Architecture", International Journal of Information Technology and Computer Science(IJITCS), Vol.8, No.6, pp.52-59, 2016. DOI: $10.5815 /$ ijitcs.2016.06.07 